III. TRAUMATIC TETANUS.

A case of tetanus occurred here a short time since, in which the disease presented the peculiarity of having followed a mere blow on the nose. It terminated fatally in a fortnight with persistent trismus, but only one attack of general spasms. The treatment was by musk and opium.

\section{SINGULAR ACCIDENTS.}

Two singular surgical accidents presented themselves in the out.patient's room. One was dislocation of the humerus into the axilla, with fracture of the clavicle on the same side-a complication very rarely observed. The other was a dislocation of the jaw, on one side only, from yawning. The patient was an old man. The dislocation was, as usual, very easily re. duced.

\section{v. DUMMREICHER'S, OR THE RAIIWAY SPIINT}

This splint, the application of which we noticed in a former number (p. 166), and which succeeded admirably in that case is again to be seen in action in this Hospital. The patient, a very old man, of intemperate habits, and threatened with delirium tremens, speaks in high terms of the comfort of the application, which keeps the parts (a fractured leg, with much bruising) in very good position.

\section{OAriginal Commumitations.}

\section{TREATMENT OF INJURIES OF THE HANDS AND FINGERS.}

By J. H. Houghton, Esq., Surgeon to the Dudley Dispensary.

Thocki not a hospital surgeon, I may be allowed to bear my testimony to the efficacy of the plan of "treatment of some cases of injury of the hands," proposed by Mr. Birkett in the Journal for December 12th. The surgery of a practitioner actively employed in the South Staffordshire coalfield affords opportunities of treating such cases equal to many hospitals ; a day hardly ever passes without some of them coming ander observation, and frequently the number is very large. Seven or eight patients with injuries of the hands and fingers, varying from a case of formidable compound fracture to some trivial wounds and lacerations, attended this morning at my surgery.

Seven years experience had fully convinced me of the clumsy and unsatisfactory means at our disposal for treating these injuries, in the shape of adhesive plaster, unguents, and poultices, when about ten years ago I began to apply the water dressing to my cases of injury of the hands and fingers; and the result was so satisfactory, that during the last ten years, with some few special exceptions, I have not used any other dressing. I am fully persuaded that no surgeon, who has not been accustomed to this mode of treatment, can have any idea of its special alaptability to the injuries in question; and I am constantly in the habit of saving parts which, under any other plan of treatment, I feel sure must be sacrificed. I have to-day carefully examined the finger of a boy, about eleven years of age, who was under my care for a compound fracture of the second phalanx of the little finger about eight years since. The case made a permanent impression on my mind for two rea sons : first, it was one of the first cases of very severe compound fracture which I saved by the water dressing treatment and secondly, I had a special interest in the patient's family. When I first saw the case, a wound on the palmar aspect divided the soft parts to at least three-fourths of their extent, the bone also being livided; the distal part of the finger literally hung by the remaining soft part, and the friends thought there was nothing to be done but to snip the parts through, and thus complete the operation. With a small piece of wood I cut a splint to fit the finger. I carefully adjusted the divided parts, and placed them on the bare splint; the finger and splint were carefully rolled together with a minute roller of dry lint. The whole was put upon a splint sufficiently long to give support from the elbow to the end of the fingers. This dressing (dry) was allowed to remain some days, and then, after well soaking, was removed, when a very slight degree of union had been effected, but the parts had regained their normal position. The special water treatment was then commenced, which consisted in the daily careful rolling of the finger on the splint, with a minute lint roller soaked in water. The patient's friends were directed to keep the roller moist by dipping it into a little tepid water. The wound did not granulate freely ; it assumed rather an unhealthy sloughy appearance, and it was some time before a healthy process was set up; yet the result was satisfactory, the parts being perfectly restored, with very little deformity remaining.

On November 17 th last, a boy was brought to my surgery, having sustained a terrible compound fracture of the second phalanx of the little finger. The wound commenced at the external side of the finger, at the proximal end close to the joint; it extended inwards and forwards to the distal end near to the second joint; the fracture took the same oblique direction. The end of the finger was retained by the skin and integuments on the inner side of the bone only, and the semidetached part lay almost at right angles to the finger itself. The wound, which had been made by a blunt piece of iron, had a very unpromising appearance. It was put up, like the former one, with diy lint; this was removed in a few days, and then the water dressing was commenced.

To-day, Dec. 15, the union of the bone is complete; the wound has nearly healed; the joints are both perfect, and the finger is straight. I have no doubt that but for the water dressings the patient would have lost his finger.

These two cases (out of hundreds similarly treated, but which seem too trivial to note) are given, because the first, from particular circumstances, made an indelible impression on $\mathrm{my}$ mind; and the second is now under treatment.

I carefully endorse the whole of the statements made in $\mathrm{Mr}$. Birkett's highly practical paper, and go a little further : for here cases in which patients have been confined to bed have been rare; with very few exceptions, the patients have attended daily at my surgery, the arm supported in a sling, and frequently the hand resting on a good lony wooden or zinc splint; in some cases, the patient is directed, when at home, to rest the hand and arm on a table, with the hand well raised. Irrigation, though an elegant, is not an essential part of the treatment; it is amply sufficient that the lint be kept moist. I generally direct a little water to be kept warm in a basin near the fire: if the fingers are the injured part, they are dipped into it; if the hand, the lint is frequently moistened with a sponge. The stripes, as Mr. Birkett justly observes, require to be applied in various ways: "sometimes in an oblique and sometimes in a vertical direction;" and in my opinion, the whole success of the treatment depends on the tact with which the lint is adjusted, and in this there is considerable art, particularly in injuries of the fingers. I use stripes of common lint, twelve or eighteen inches long, from one-half to threequarters of an inch wide, and rolled up like common rollers; these are well soaked before they are applied. If I have to deal with a simple wound or laceration, the finger is simply rolled with the roller; but if I have to deal with a compound fracture, the fractured finger is placed on a small splint of wood or gutta percha (adapted to the particular case), and the roller is applied round the finger and splint together. The plasticity of a finger so handled is marvellous; and by altering and arranging the position of the splint and the roller, almost any deviation from the proper position of the bones or soft parts may be rectified, the exuberance of granulations re strained, and the shape of the part maintained.

I am pleased to see a gentleman of Mr. Birkett's position advocating what some will consider a very unsurgical, though a very beneficial course, as illustrated in Case 4; I mean, leaving the projecting ends of bones (of the hands and fingers), from which the integuments have been torn, to be covered by granulation instead of removing the part. I have long adopted this plan; and, though it is by no means a brilliant practice, I am sure it is far more conducive to the patient's welfare, than the more orthodox and dazzling recourse to operative proceedings.

\section{A CASE OF LARGE GALL-STONE ESCAPING THROUGH THE WALLS OF THE ABDOMEN AFTER MANY MONTHS SUFFERING, WITH ULTIMATE RECOVERY.}

By Draper Mackinder, M.D., F.R.C.S., Gainsborough.

ON August 28th, 1856, I was requested to visit a Mrs. B., a delicate lady, aged 75 years, who had frequently complained of a pain in her right side, but now seemed to be suffering from an attack of acute hepatitis, for which $I$ attended her until October 23rd, when she became convalescent. 